\title{
Features of Triglycerides Isomerization in the Process of Hydrogenization of Cottonseed Oils
}

\author{
Sh. M. Khodjiev ${ }^{1 *}$, K. K. Sattorov ${ }^{2}$, K. Kh. Majidov ${ }^{1}$ and N. K. Majidova ${ }^{1}$ \\ ${ }^{1}$ Bukhara Engineering-Technological Institute, Bukhara city, Uzbekistan \\ ${ }^{2}$ Gulistan State University, Gulistan city, Uzbekistan \\ *Corresponding author
}

\begin{abstract}
A B S T R A C T

\begin{tabular}{l} 
Ke y w o r d s \\
Technology of \\
hydrogenation, \\
Catalysts, \\
$\begin{array}{l}\text { Isomerization } \\
\text { processes, Trans- } \\
\text { isomerized fatty } \\
\text { acids, Desired fats }\end{array}$ \\
\hline Article Info \\
\hline $\begin{array}{l}\text { Accepted: } \\
\text { 22 June } 2020 \\
\text { Available Online: } \\
\text { 10 July 2020 }\end{array}$ \\
\hline
\end{tabular}

Introduction

Processes of hydrogenation of vegetable oils and fats are the main technological stages of the catalytic modification of raw materials (Arutyunyan et al., 1985; Anderson, 1978; Glushenkova, 1979). In domestic and foreign practice, numerous studies are known in this direction (Zabrovsky, 1999; Allen 1980; Majidov, 1987; Akramov, 2008; Majidova, 2017). However, in well-known studies, little attention has been paid to studying the

peculiarities of triglyceride isomerization during the hydrogenation of vegetable oils and fats. Therefore, the study of these issues by the results of analysis and evaluation of their own experimental materials (Majidova, 2017;Majidov, 1979; Satarov, 1993) is of scientific and practical interest.

Purpose of the work is aimed at studying the features of triglyceride isomerization during the hydrogenation of vegetable oils on effective catalysts.
\end{abstract}




\section{Materials and Methods}

The processes of hydrogenation of vegetable oils were carried out in flow-type column plants and in industrial autoclaves (Arutyunyan et al., 1983). To analyze the raw materials and the resulting products, modern methods of physicochemical research were used (Arutyunyan et al., 1983; Majidova, 2017).

\section{Results and Discussion}

From a chemical point of view, the process of hydrogenation of fats is much more complicated than the reaction of addition of hydrogen (13), since the catalysts used in this process can also accelerate other chemical transformations (Bhattacharyya et al., 1987; Melamud, 1982; Kiperman, 1979), among which isomerization processes, especially the following types, are most important from a practical point of view:

- shifting of double (ethylene) bonds along the carbon chain of the molecule (positional isomerization):

$\mathrm{R}_{1}-\mathrm{CH}_{2}-\mathrm{CH}=\mathrm{CH}-\mathrm{R}_{2} \rightarrow \mathrm{R}_{1}-\mathrm{CH}=\mathrm{CH}$ $-\mathrm{CH}_{2}-\mathrm{R}_{2}$

- formation of trans-isomers (geometric isomerization):

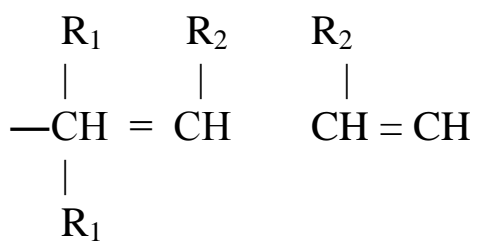

Because of changes in the structure of fatty acid radicals, the physical-chemical and technological properties of triglycerides change. In other words, due to isomerization, it is possible to obtain oil-and-fat mixture with the same iodine numbers, but with completely different physical-chemical properties (hardness, melting point, and crystallization dynamics) (Satarov, 1993; Majidova, 2018).

Tables 1 and 2 show the melting points of cisforms and trans-forms for various positional isomers of octadecenoic and octadecadienoic acids. From the above data, it can be seen that in most cases the melting temperature of trans-isomers is significantly higher than the melting temperature of cis-isomers. Exception is cis-isomers with a double bond strongly shifted from the natural position.

It is necessary to consider more particularly the general mechanism of the hydrogenation process to understand the principle of isomerization in the hydrogenation process.

According to the author, the most realistic mechanism of the hydrogenation process is described in (Kiperman, 1979).

At the beginning of the process, dissolved in oil hydrogen is adsorbed on nickel, which is in reduced form and have lack of electrons in 3d-orbitals. During sorption, hydrogen molecules dissociate into very active atoms. The hydrogenation reaction can go in several directions.

Adsorbed triglyceride molecule is able to participate in two processes.

Desorption reaction: molecule is detached from the catalyst without undergoing changes compared to the initial state.

Reaction with atomic hydrogen: hemihydrogenated intermediate compound is formed. The interaction of ethylene bonds with atomic hydrogen proceeds stepwise, and the formation of unstable intermediate "hemihydrogenated" complex is a reversible reaction: 


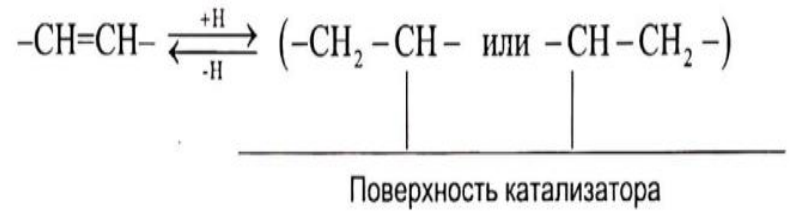

(catalyst surface)

Hemi-hydrogenated intermediate compound can react in four directions, in each of which the processes are reversible.
The hydrogen atom, just attached to the triglyceride, can go back to nickel without causing noticeable changes.

Both methylene groups adjacent to the chemisorbed carbon atom are activated in the hemi-hydrogenated complex. In this case, compounds whose ethylene bond is shifted from the initial one by one carbon atom in one direction or another (positional isomers) are formed:

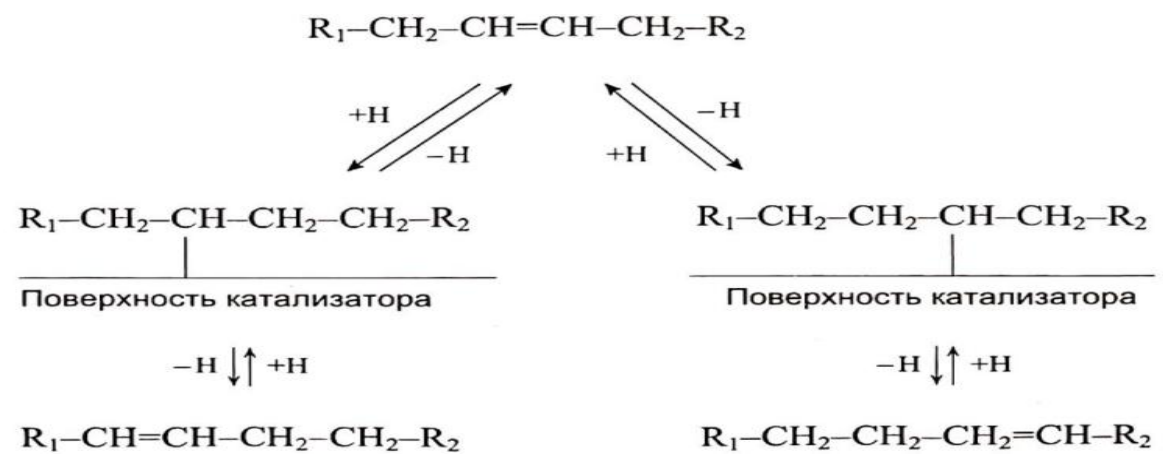

Table.1 Melting temperature of isomers of octadecenoic $\left(\mathrm{C}_{18: 1}\right)$ acid

\begin{tabular}{|c|c|c|}
\hline \multirow{2}{*}{$\begin{array}{c}\text { Position of double } \\
\text { bond }\end{array}$} & \multicolumn{2}{|c|}{ Melting temperature, ${ }^{\circ} \mathrm{C}$} \\
\hline 2 & of cis-isomers & of trans-isomers \\
\hline 3 & 49 & 58 \\
\hline 4 & 50 & 65 \\
\hline 5 & 46 & 59 \\
\hline 6 & 14 & 47 \\
\hline 7 & 29 & 54 \\
\hline 8 & 12 & 45 \\
\hline 9 & 24 & 53 \\
\hline 10 & 10 (oleic acid) & 54 \\
\hline 11 & 24 & (elaidic acid) \\
\hline 12 & 13 & 54 (vacene acid) \\
\hline 13 & 27 & 52 \\
\hline 14 & 26 & 54 \\
\hline 15 & 42 & 59 \\
\hline 16 & 40 & 66 \\
\hline 17 & 54 & 56 \\
\hline
\end{tabular}


Table.2 Melting temperature of isomers of octadecadienoic $\left(\mathrm{C}_{18: 2}\right)$ acid

\begin{tabular}{|c|c|c|c|}
\hline $\begin{array}{c}\text { Position of } \\
\text { double bond }\end{array}$ & $\begin{array}{c}\text { Melting temperature } \\
\text { of cis-cis-isomer }\end{array}$ & $\begin{array}{c}\text { Position of double } \\
\text { bond }\end{array}$ & $\begin{array}{c}\text { Melting temperature } \\
\text { of trans-trans-isomer }\end{array}$ \\
\hline 2.5 & 35 & 5.12 & 27 \\
\hline 3.6 & 22.5 & 6.12 & 40 \\
\hline 4.7 & 11.5 & 7.12 & 27 \\
\hline 5.8 & -8.5 & 8.12 & 39 \\
\hline 6.9 & -10 & 9.12 & 25.5 \\
\hline 7.10 & -15 & 10.12 & 25 \\
\hline 8.11 & -15 & 6.13 & 37.5 \\
\hline 9.12 & -8.5 (linoleic acid) & 6.11 & 29 \\
\hline 10.13 & -10.5 & 6.10 & 41 \\
\hline 11.14 & 5 & 6.9 & 15 \\
\hline 12.15 & 18 & 6.8 & 52.5 \\
\hline 13.16 & 26 & & \\
\hline 14.17 & 37 & & \\
\hline
\end{tabular}

Table. 3 Change in the properties of hydrogenates of sunflower oil as the triglycerides are saturated

\begin{tabular}{|l|c|c|c|c|c|c|}
\hline \multicolumn{1}{|c|}{ Indicator } & \multicolumn{7}{|c|}{ Value of indicator } \\
\hline $\begin{array}{l}\text { Iodine number of the hydrogenate, } \\
\text { I } / 100 \mathrm{~g}\end{array}$ & 96 & 92 & 81 & 77 & 73 & 69 \\
\hline Selectivity of hydrogenation, \% & 98 & 98 & 97 & 95 & 90 & 85 \\
\hline The content of trans-isomers, \% & 29 & 31 & 38 & 40 & 43 & 42 \\
\hline Increase in content of stearic acid, \% & 0 & 0.9 & 1.6 & 3.5 & 6.0 & 13.8 \\
\hline Residual content of linoleic acid, \% & 21 & 17 & 5 & 3 & 0 & 0 \\
\hline Melting temperature, ${ }^{\circ} \mathrm{C}$ & 25 & 29 & 33 & 34 & 35 & 37 \\
\hline Hardness but Kaminsky, $\mathrm{g} / \mathrm{cm}$ & 70 & 140 & 270 & 300 & 400 & 700 \\
\hline
\end{tabular}

Table.4 Changes in the properties of sunflower oil during its hydrogenation on a reusable catalyst

\begin{tabular}{|l|c|c|c|c|}
\hline \multicolumn{1}{|c|}{ Indicator } & \multicolumn{4}{|c|}{ Value of indicator } \\
\hline $\begin{array}{l}\text { Iodine number of the hydrogenate, } \\
\text { I } / 100 \mathrm{~g}\end{array}$ & 99 & 95 & 89 & 80 \\
\hline Selectivity of hydrogenation, \% & 99 & 97 & 96 & 95 \\
\hline The content of trans-isomers, \% & 35 & 50 & 55 & 63 \\
\hline Increase in content of stearic acid, \% & 0 & 0 & 3 & 3 \\
\hline Residual content of linoleic acid, \% & 24 & 18 & 12 & 6 \\
\hline Melting temperature, ${ }^{\circ} \mathrm{C}$ & 24 & 26 & 29. & 36 \\
\hline Hardness by Kaminsky, $\mathrm{g} / \mathrm{cm}$ & - & - & 150 & 600 \\
\hline
\end{tabular}


Fig.1 Accumulation of trans isomers during hydrogenation of sunflower oil under different conditions: 1 - catalyst, $0.05 \%$ in oil, $180{ }^{\circ} \mathrm{C} ; 2$ - reusable catalyst, $0.1 \%$ nickel in oil, $200{ }^{\circ} \mathrm{C}$

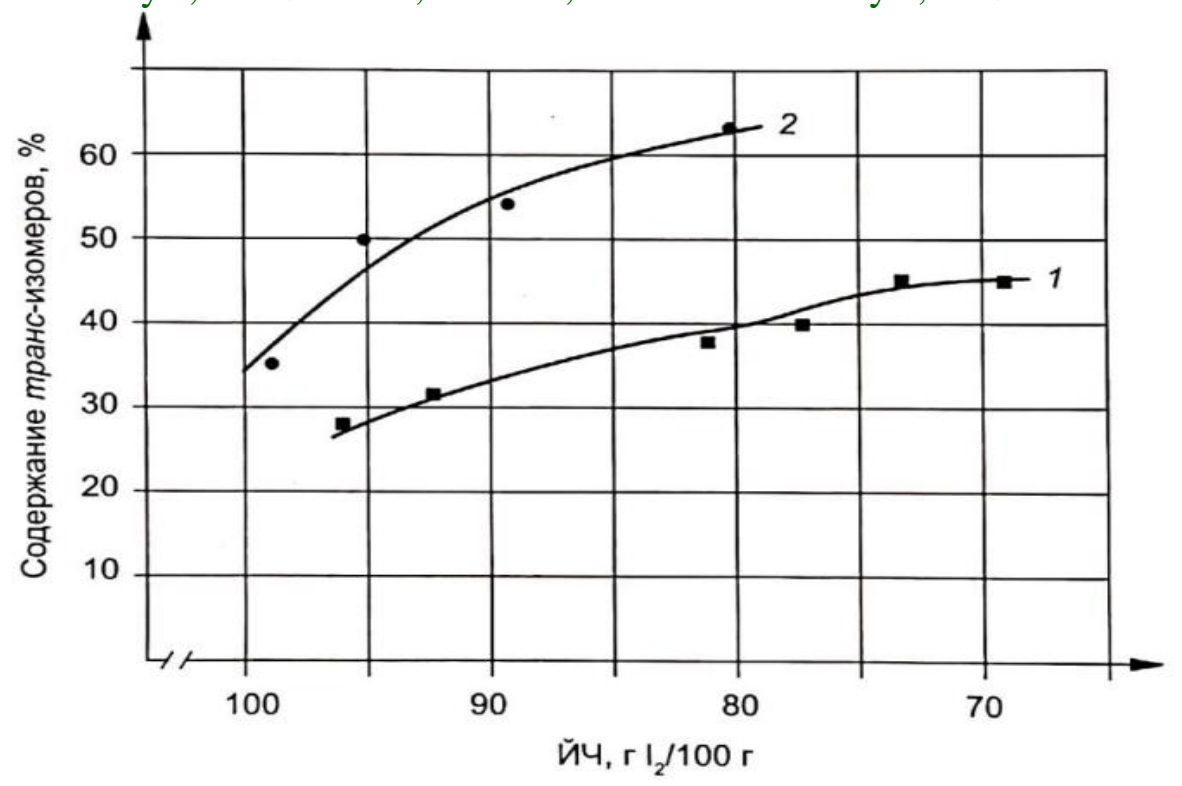

The above reactions, i.e. chemisorption of the ethylene bond, its "hemi-hydrogenation", dehydrogenation of the "hemi-hydrogenated" complex and desorption of the resulting unsaturated compound are repeated many times. If the rate of the final stage of hydrogenation is small and the thermodynamic conditions favor the shift of ethylene bonds, then products of partial hydrogenation accumulate positional isomers with bonds more removed from the initial position.

In the case of a $\pi$-bond breaking, free rotation of carbon chains around the remaining single $\sigma$-bond $=\mathrm{CH}-\mathrm{CH} 2-$ hemi-hydrogenated complex is possible. The intensity of rotation depends on the structure of the carbon chains, on the process temperature, on the nature and structure of the catalyst.

The spatially preferred position of the substituents is their location on opposite sides of the $\mathrm{C}-\mathrm{C}$ bond. If the hydrogen atom passes from the hemi-hydrogenated complex back to the catalyst in this case, then the trans-isomer is formed:

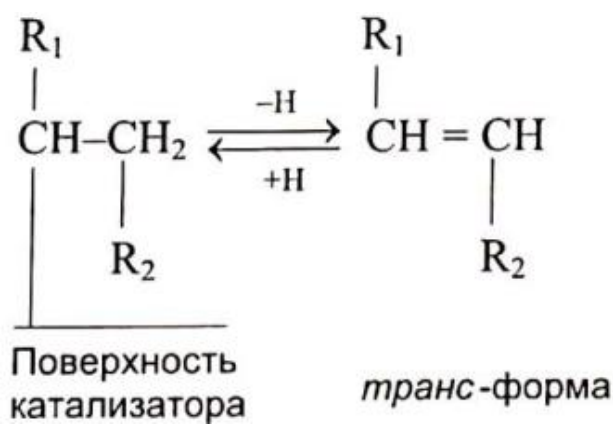

If the thermodynamic conditions do not allow rotation around the $\mathrm{C}-\mathrm{C}$ bond in the hemihydrogenated molecule, then the cis-isomer is formed:

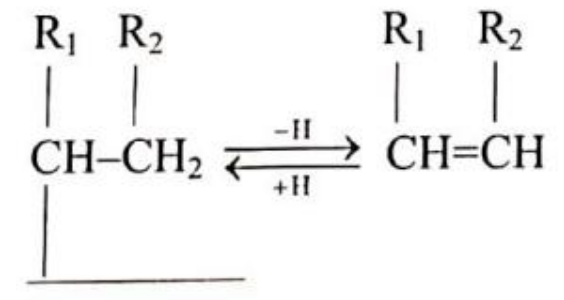

Поверхность

катализатора

цис-форма

The main reaction is to attach a second hydrogen atom to the hemi-hydrogenated complex, after which the reaction product, in which a saturated bond is formed instead of a double bond, leaves the catalyst and passes 
into the oil volume:

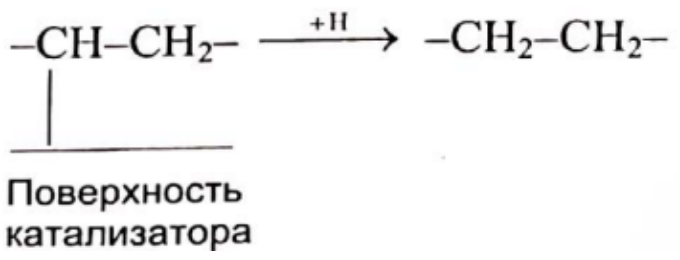

The cis-configuration is energetically less beneficial than the trans configuration. However, the natural organic compounds of the unsaturated ranks, including unsaturated fatty acids of natural vegetable oils and animal fats, are overwhelmingly in the cisform.

Trans-isomers are formed in different quantities in the industrial hydrogenation of vegetable oils. The degree of transisomerization mainly depends on the hydrogenation conditions: temperature, type, amount and activity of the catalyst, pressure and amount of hydrogen, intensity of mixing. In practice at incomplete hydrogenation the content of trans isomers is limited by the thermodynamics of cis-trans equilibrium and reaches a maximum of $75 \%$ of the total number of double bonds.

The positional trans-isomers of octadecenoic acid in hydrogenated vegetable oils obey the Gaussian distribution centered near trans-9, trans-10, trans-11, trans-12 (Sokolsky, 1979).

Table 3 shows the characteristics of the oiland-fat mixtures obtained by hydrogenation of sunflower oil to various iodine numbers, including the content of trans-isomers.

In the production of margarine products by traditional methods, it is necessary to have selectively hydrogenated vegetable oils, which are characterized by a very high content of geometric and positional isomers of unsaturated acids (the concentration of trans-isomers of unsaturated fatty acids is 40$55 \%$ ), high hardness and a relatively low melting temperature. To obtain such characteristics, industrial hydrogenation of vegetable oils is carried out in the least intensive technological mode: in the presence of small amounts of catalyst with reduced activity and high isomerizing ability, with low hydrogen pressure, weak stirring, and long contact time of the oil with the catalyst.

Repeated use of nickel catalysts or their modification with nickel oxide is accompanied by decrease in the hydrogenating activity of the catalysts and increase in their isomerizing activity. The use of modified, reusable (spent) nickel catalysts is the basis for the industrial method of selective hydrogenation and isomerization of fats in autoclave battery for the purpose to obtain oil-and-fat mixture for margarine products.

Characteristics of the products obtained by hydrogenation of sunflower oil on reused N800 catalyst are shown in Table 4 (Satarov, 1993). The accumulation of trans-isomers in oil-and-fat mixture depending on the hydrogenation depth in using "fresh" and spent catalyst is compared in Fig. 1.

Conclusions are as follows:

Isomerization of triglycerides in the hydrogenation of cottonseed oils depend on the location of the double bond in the carbon chain

High accumulation of trans-isomers in oiland-fat mixture is observed during hydrogenation of oil in the "fresh" and spent catalyst

\section{References}

Akramov O.A. Modification of cottonseed oil on efficient catalysts. Abstract of dissertation of candidate of technical sciences. Tashkent chemical- 
technological institute, 2008, p. 26

Allen R.R. and Covey J.E. Hydrogenation of vegetable oils with sulphur treated catalysts. -JAOCS. 1980. 57. No. 1. P.115A.

Anderson J. The structure of metal catalysts. M.: Mir, 1978. p. 480

Arutyunyan N.S., Arisheva E.A., Yanova L.I. et.al. Technology of fat processing. M.: Agropromizdat. 1985, p. 368

Arutyunyan N.S., Arisheva E.A., Yanova L.I., Kamyshan M.A. Laboratory workshop on fat processing technology. -M.: Light and food industry, 1983. p. 150

Bhattacharyya D.K., Majumdar., Roy S., Basu R. Margarines from palm oil and its fractions., Oleaglneux. 1987. 42. No. 6. P.253 258.

Glushenkova A.I., Markman A.L. Hydrogenation of fats. Tashkent, Fan, 1979, p. 144

Kiperman S.L. The basics of chemical kinetics in heterogeneous catalysis. M.: Chemistry, 1979. p. 352.

Majidova N.K. Improving the technology of hydrogenation of cotton oil on a new generation of catalysts. 12th International scientific conference of bachelor and master students "Technique and technology of food production". -Mogilev, 2018, p.77-78.

Majidova N.K. Solid Fats with a Minimum Content of Trans Acids. Journal "Advances in Biochemistry and Biotechnology", USA, 2017.

Majidova N.K., Kadirov Y.K. Catalysts in the Hydrogenation of Oils Technology.
Journal "Advances in Biochemistry and Biotechnology", USA, 2017.

Majidov K.Kh. Investigation of the continuous hydrogenation of cottonseed oil on alloyed nickelcopper catalysts in order to obtain food grade of oil-fat mixtures. Abstract of dissertation of candidate of technical sciences. L. 1979, p.20.

Majidov K.Kh. Research and improvement of the technology of hydrogenation of cottonseed oil on modified alloyed stationary catalysts. Abstract of dissertation of doctor of sciences. L.: 1987, p.48

Melamud N.L. Improving the technology and expanding the raw material base for the production of hydrogenated fats. Abstract of dissertation of candidate of technical sciences in the form of a scientific report. -L.: VNIIZH, 1982. p. 60.

Satarov K.K. Research and development of technology for the continuous hydrogenation of fats using a stationary catalyst as a precontact. Abstract of dissertation of candidate of technical sciences. -SPb., VNIIZH, 1993, p. 27.

Sokolsky D.V., Sokolskaya A.M. Hydrogenation catalyst metals. AlmaAta: Science, 1979. p. 240

Zabrovsky G.P., Klyuchkin V.V. Catalytic modification of natural oils, fats, and obtaining food products from them. $\mathrm{SPb} .:$ VNIIZH, 1999, p. 336

\section{How to cite this article:}

Khodjiev, Sh. M., K. K. Sattorov, K. Kh. Majidov and Majidova, N. K. 2020. Features of Triglycerides Isomerization in the Process of Hydrogenization of Cottonseed Oils. Int.J.Curr.Microbiol.App.Sci. 9(07): 2951-2957. doi: https://doi.org/10.20546/ijcmas.2020.907.348 